\title{
Biomarker Discovery for Immunotherapy of Pituitary Adenomas: Enhanced Robustness and Prediction Ability by Modern Computational Tools
}

\author{
Qingxia Yang ${ }^{1,2}$, Yunxia Wang ${ }^{2}$, Song Zhang ${ }^{2}$, Jing Tang ${ }^{1,2}$, Fengcheng $\mathrm{Li}^{2}$, Jiayi Yin ${ }^{2}, \mathrm{Yi} \mathrm{Li}^{2}$, \\ Jianbo $\mathrm{Fu}^{2}$, Bo Li ${ }^{1}$, Yongchao Luo ${ }^{2}$, Weiwei Xue ${ }^{1, * \mathbb{D}}$ and Feng $\mathrm{Zhu}{ }^{1,2, * \mathbb{D}}$ \\ 1 School of Pharmaceutical Sciences, Chongqing University, Chongqing 401331, China; \\ yangqx@cqu.edu.cn (Q.Y.); 20132902008@cqu.edu.cn (J.T.); libcell@cqu.edu.cn (B.L.) \\ 2 College of Pharmaceutical Sciences, Zhejiang University, Hangzhou 310058, China; lfwyx@zju.edu.cn (Y.W.); \\ zhangsong_@zju.edu.cn (S.Z.); lifengcheng@zju.edu.cn (F.L.); yinjiayi@zju.edu.cn (J.Y.); \\ liyi@email.com (Y.L.); fujianbo@zju.edu.cn (J.F.); luo.yongchao@foxmail.com (Y.L.) \\ * Correspondence: xueww@cqu.edu.cn (W.X.); zhufeng@zju.edu.cn (F.Z.); \\ Tel.: +86-(0)571-8820-8444 (W.X. \& F.Z.)
}

Received: 9 December 2018; Accepted: 26 December 2018; Published: 3 January 2019

\begin{abstract}
Pituitary adenoma (PA) is prevalent in the general population. Due to its severe complications and aggressive infiltration into the surrounding brain structure, the effective management of PA is required. Till now, no drug has been approved for treating non-functional PA, and the removal of cancerous cells from the pituitary is still under experimental investigation. Due to its superior specificity and safety profile, immunotherapy stands as one of the most promising strategies for dealing with PA refractory to the standard treatment, and various studies have been carried out to discover immune-related gene markers as target candidates. However, the lists of gene markers identified among different studies are reported to be highly inconsistent because of the greatly limited number of samples analyzed in each study. It is thus essential to substantially enlarge the sample size and comprehensively assess the robustness of the identified immune-related gene markers. Herein, a novel strategy of direct data integration (DDI) was proposed to combine available PA microarray datasets, which significantly enlarged the sample size. First, the robustness of the gene markers identified by DDI strategy was found to be substantially enhanced compared with that of previous studies. Then, the DDI of all reported PA-related microarray datasets were conducted to achieve a comprehensive identification of PA gene markers, and 66 immune-related genes were discovered as target candidates for PA immunotherapy. Finally, based on the analysis of human protein-protein interaction network, some promising target candidates (GAL, LMO4, STAT3, PD-L1, TGFB and TGFBR3) were proposed for PA immunotherapy. The strategy proposed together with the immune-related markers identified in this study provided a useful guidance for the development of novel immunotherapy for PA.
\end{abstract}

Keywords: pituitary adenomas; immunotherapy; immune-related gene markers; transcriptomics

\section{Introduction}

Pituitary adenoma (PA) accounts for approximately $8-15 \%$ of intracranial tumors [1-3] and its prevalence is estimated to be $\sim 14-22 \%$ by autopsy and radiological studies [4-6]. Due to its aggressive infiltration into the surrounding brain structure and its severe complications (such as Cushing's disease, hyperprolactinemia, and acromegaly), the effective managements of PA are still required [7-9], which involves trans-sphenoidal surgery, radiotherapy, and medicine [10]. Trans-sphenoidal surgery is reported as sometimes contraindicated or ineffective [11], and the application of radiotherapies is 
greatly limited by its subsequent hypopituitarism [11]. So far, medical therapy has been expected and emerged to provide the treatment of enhanced efficacy, safety and tolerance [11-13], and several drugs have already been approved by U.S. FDA (Food and Drug Administration) for treating certain complications of PA [14-16]. For example, cabergoline, octreotide, and pasireotide have FDA approval for the management of hyperprolactinemia, acromegaly, and Cushing's disease, respectively [17-20]. Apart from the drugs aiming at PA complication, temozolomide is found to penetrate well into central nervous system, and therefore has been tested in clinical trial (Phase II) for treating PAs [21-24].

However, those approved therapeutics primarily focus on managing the complication of PA rather than PA itself $[17,18]$, which are incapable of removing the tumor cells and are ineffective in turning the pituitary back to its normal state [25]. The therapeutics designed for the direct treatment of PA are primarily chemotherapy [21], kinase inhibitor [26-29], and monoclonal antibody [30-32]. Till now, chemotherapy and kinase inhibitors have emerged as the most promising candidates with temozolomide and lapatinib in clinical developments [21,26,33], but they suffer from severe myelotoxicity, mental disturbances or cardiac dysrhythmia that can substantially affect the approval processes of these clinical candidates [34-36]. So far, no effective drug has been developed for treating non-functional pituitary tumors, and the removal of cancerous cells directly from the pituitary is still under experimental investigation [37-39]. It is thus crucial to discover a new strategy for PA treatment. With the advent of immunotherapy [40,41], the management of PA base for this new strategy has become the focus of current research [1,30]. In other words, due to its high specificity and good safety profiles [42], immunotherapy stands as one of the most promising alternatives for treating PAs that are resistant or refractory to the standard treatments [43-46].

Although no immunotherapy of PA has been approved yet, various studies have been carried out to discover immune-related genes or target candidates. Particularly, as an immunomodulatory peptide, protein galanin $(G A L)$ is substantially suppressed in the tissue of PA patients compared with those in healthy pituitaries [47]. Increased levels (both mRNA and protein) of programmed death-ligand 1 (PD-L1, the immunosuppressive protein) are observed in tumor tissue of PA patients [43], which can induce immune evasion by desensitizing the recognition and elimination of cancer cells via $\mathrm{CD} 8^{+}$ lymphocytes [48]. Transforming growth factor-beta (TGFB) was discovered as one of the chief immune suppressive mediators of prolactin (PRL) secretions and PA proliferation [49,50]. Apart from the above studies, a variety of transcriptomics analyses (demonstrated in Table 1) have been conducted to identify the differentially expressed genes (DEGs) between PA patients and normal ones [51-54]. Due to their Omics-based nature, these analyses can accelerate more effectively the discovery of target candidates compared with previous studies. However, because of the limited number of both the patients and controls in each analysis ( 4-16 samples for patients and $\sim 0-9$ for healthy individuals shown in Table 1), the lists of DEGs identified from different analyses are reported to be highly inconsistent $[55,56]$, which asks for substantial enhancements of the robustness of the identified PA biomarkers [57,58]. Moreover, no Omics study has been conducted to reveal immune-related genes and mechanisms underlying PA's development, which is essential for the discovery of promising targets for PA immunotherapy [59]. Thus, it is urgently needed to systematically identify the immune-related DEGs based on the comprehensive analysis of the PA-based Omics datasets with significantly enlarged sample size (for both PA patients and healthy individuals) [60].

Table 1. Pituitary adenomas related microarray datasets collected for analysis in this study.

\begin{tabular}{ccccc}
\hline GEO ID & Samples PA:NP ${ }^{a}$ & $\begin{array}{c}\text { Description of the Collected Datasets for } \\
\text { Studying on }\end{array}$ & $\begin{array}{c}\text { Microarray } \\
\text { Platform }\end{array}$ & $\begin{array}{c}\text { Reference of the } \\
\text { Studied Datasets }\end{array}$ \\
\hline GSE2175 & $4: 1$ & $\begin{array}{c}\text { GeneChip arrays of } 1 \text { healthy and 4 pituitary } \\
\text { adenoma samples }\end{array}$ & HG-U133A & [61] \\
\hline GSE22812 & $13: 0$ & $\begin{array}{c}\text { Genomic hybridization arrays of 13 pituitary } \\
\text { adenoma samples }\end{array}$ & GE Healthcare & [53] \\
\hline GSE26966 & $14: 9$ & GeneChip arrays of 9 healthy and 14 pituitary \\
adenoma samples & HG-U133_Plus_2 & [62] \\
\hline
\end{tabular}


Table 1. Cont.

\begin{tabular}{ccccc}
\hline GEO ID & Samples PA:NP ${ }^{a}$ & $\begin{array}{c}\text { Description of the Collected Datasets for } \\
\text { Studying on }\end{array}$ & $\begin{array}{c}\text { Microarray } \\
\text { Platform }\end{array}$ & $\begin{array}{c}\text { Reference of the } \\
\text { Studied Datasets }\end{array}$ \\
\hline GSE36314 & $4: 3$ & $\begin{array}{c}\text { Genome arrays of 3 healthy and 4 pituitary } \\
\text { adenoma samples }\end{array}$ & HG_U95Av2 & [63] \\
\hline GSE4237 & $10: 0$ & $\begin{array}{c}\text { Affymetrix oligo arrays of 10 pituitary } \\
\text { adenoma samples }\end{array}$ & HG-U133_Plus_2 & [52] \\
\hline GSE46311 & $16: 0$ & Affymetrix Human Gene arrays of 16 pituitary & HuGene-1_0-st & [51] \\
\hline adenoma samples & Agilent arrays of 3 healthy and 7 pituitary \\
adenoma samples & Agilent-hgug4112a & [64] \\
\hline
\end{tabular}

In this study, a strategy of direct data integration (DDI) was proposed to combine available PA microarray datasets for significantly enlarging the sample size. To test the impact of the DDI strategy on the classification ability and the robustness of identified DEGs, its performance and disease relevance were first evaluated by comparing with previously published datasets. Then, all currently available PA-related microarray datasets were directly integrated to achieve comprehensive identification of DEGs between PA patients and healthy individuals. Finally, the immune-related genes were annotated from DEGs, which could be further studied as target candidates for PA immunotherapy. The strategy proposed together with the immune-related DEGs identified in this study provided a useful guidance for future immunotherapy.

\section{Results and Discussion}

\subsection{The Level of PA-Relevance of the DEGs Identified by Different Analytical Strategies}

Several studies have been conducted to identify the DEG capable of distinguishing PA patients from healthy people [51-53]. Due to their limited number of disease and healthy samples, the DEGs identified in different studies are reported to be highly inconsistent [55], which requires substantial enhancement in the robustness of the identified DEGs [57,58]. Thus, it is necessary to evaluate the impact of sample size on the robustness and disease relevance of the identified DEGs. In this study, three analytical strategies were proposed based on the construction of three datasets. As illustrated in Figure 1, the datasets included: (A) GSE51618, (B) GSE26966, (C) DDI of five datasets GSE22812, GSE26966, GSE4237, GSE46311, and GSE51618. Clearly, the sample size of dataset C (60 cases and 12 controls) is significantly larger than that of the remaining two (seven cases and three controls for dataset A; 14 cases and six controls for dataset B). By using this DDI strategy, it is now feasible to discuss the effectiveness of this strategy on enhancing the robustness of identified DEGs and systematically assess the impact of sample size on the resulting DEGs.

As the first assessment, the level of PA relevance was reviewed and discussed for three different analytical strategies. Three lists of DEGs were identified using three different strategies by the linear models and empirical Bayes (LMEB, fold change $>1.5$ and adjusted $p$-value $<0.05$ ). Top-ranked DEGs (top five for upregulated and another top five for downregulated) and their relevance to PAs were reviewed by comprehensive literature review. As shown in Supplementary Table S1, 3, 4, and 7 of the top 10 DEGs (identified by datasets A, B, and C, respectively) had been reported to be relevant to PAs. Moreover, 32, 56, and 43 KEGG (Kyoto Encyclopedia of Genes and Genomes) pathways were enriched using DEGs identified from datasets A, B, and C, respectively. The top 10 ranked pathways and their relevance to PA were comprehensively reviewed. As shown in Supplementary Table S2, 3, 4, and 7 of the top 10 ranked pathways (identified by datasets A, B, and C, respectively) had been reported to be closely relevant to PAs. Furthermore, top 10 GO (gene ontology) molecular functions (MFs) and biological processes (BPs) and their relevance to PA were comprehensively reviewed. As shown in Supplementary Tables S3 and S4, 5, 5, and 7 of the top 10 ranked BPs and 4, 4, and 6 of the top 10 ranked MFs (identified by datasets $\mathrm{A}, \mathrm{B}$, and $\mathrm{C}$, respectively) had been reported to be relevant to PAs. 
Overall, these findings indicated that all three strategies used in this study showed a certain level of PA relevance in their identified DEGs. The DDI strategy presented a higher percentage of PA-relevant DEGs, pathways, and GO terms, which indicated the enhanced disease relevance of this strategy comparing to that of the single dataset-based one.

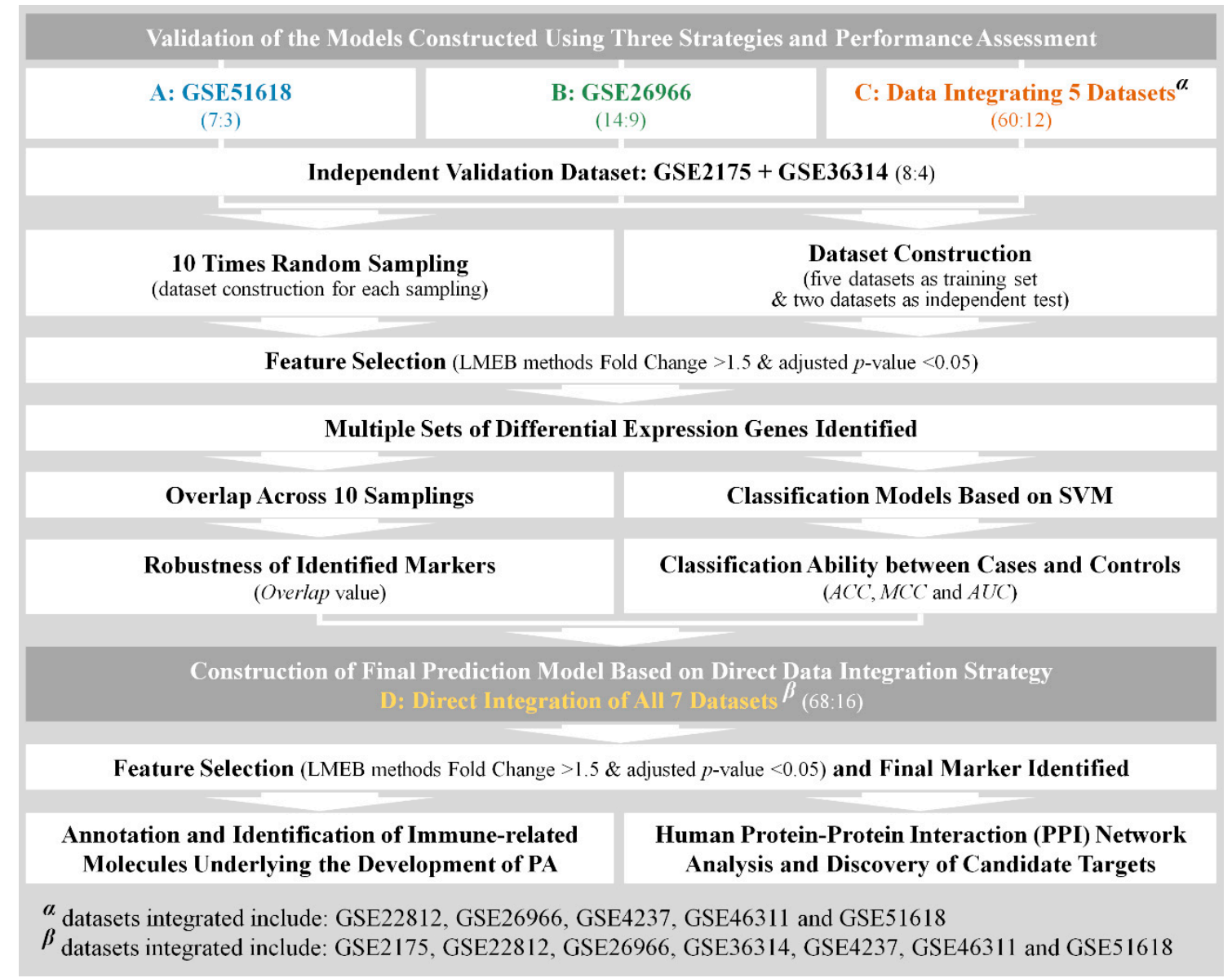

Figure 1. A schematic representation of the direct data integration (DDI) strategy adopted in this study. Four datasets (A: GSE51618, B: GSE26966, C: Data Integrating 5 Datasets and D: Direct Integration of All 7 Datasets) were labeled by blue, green, orange and yellow color, respectively. LMEB: Linear models and empirical Bayes; ACC: accuracy; MCC: Matthews correlation coefficient; AUC: area under the curve.

\subsection{Evaluating the Classification Abilities of the DEGs Identified by Different Analytical Strategies}

Classification models are frequently constructed in current transcriptomics studies for predicting samples of various disease status $[65,66]$ or assessing the reliability of identified gene markers $[67,68]$. The capacity of the constructed classification model was evaluated by various metrics including accuracy $(A C C)$, sensitivity $(S E N)$, specificity $(S P E)$, Matthews correlation coefficient $(M C C)$, receiver operating characteristics (ROC), and area under ROC curve (AUC value) [69-71]. As shown in Table 2, there was great variation in each assessment metric among the analytical strategies. Particularly, ACCs, SENs, SPEs, and MCCs were in the ranges of $\sim 0.67-0.92, \sim 0.50-0.88, \sim 0.75-1.00$, and $\sim 0.35-0.84$ among strategies, respectively. The metrics ACC and MCC were frequently used in current Omics study to evaluate correctness [72] and stability [73] of the constructed models. As demonstrated in Table 2, the ACC of DDI strategy (0.92) was substantially higher than that of the single dataset-based strategies (both are 0.67$)$. Similar to ACC, MCC of DDI strategy (0.84) was discovered to be higher than that of the other two $(0.35$ and 0.50 , respectively). 
Table 2. Prediction ability of three classifiers. These classifiers were build using GSE51618, GSE26966 and the combination of GSE22812, GSE26966, GSE4237, GSE46311, and GSE51618. Prediction ability was assessed by the integration of GSE36314 and GSE2175 as the independent validation dataset.

\begin{tabular}{cccccccccc}
\hline Datasets & TP $^{a}$ & FN $^{a}$ & TN $^{a}$ & FP $^{a}$ & ACC $^{b}$ & SEN $^{b}$ & SPE $^{b}$ & MCC $^{b}$ & AUC $^{c}$ \\
\hline A: GSE51618 & 4 & 4 & 4 & 0 & 0.67 & 0.50 & 1.00 & 0.50 & 0.75 \\
B: GSE26966 & 5 & 3 & 3 & 1 & 0.67 & 0.63 & 0.75 & 0.35 & 0.72 \\
C: DDI Strategy & 7 & 1 & 4 & 0 & 0.92 & 0.88 & 1.00 & 0.84 & 0.97 \\
\hline
\end{tabular}

${ }^{a}$ TP: true positive; TN: true negative; FP: false positive; FN: false negative. ${ }^{b}$ ACC: accuracy; SEN: sensitivity; SPE: specificity; MCC: Matthews correlation coefficient. ${ }^{c}$ AUC: area under the curve.

Apart from $A C C$ and $M C C$, the ROC and $A U C$ were two other popular metrics widely used to assess ability for classification, which were acknowledged to achieve comprehensive performance evaluations. As shown in Figure 2, the ROC curves and AUC values of three strategies were compared. Grey diagonals represented an invalid model with the corresponding AUC value equaled 0.5. As shown in Figure 2, the AUC value of the DDI strategy (0.97) was substantially higher than that of the others ( 0.75 and 0.72 , respectively), which were similar to the results assessed by ROC curves. In conclusion, this finding indicated that classification correctness (assessed by ACC, ROC, and AUC) and prediction stability (evaluated by MCC) of DDI strategy were found consistently better compared with those strategies based on single dataset.
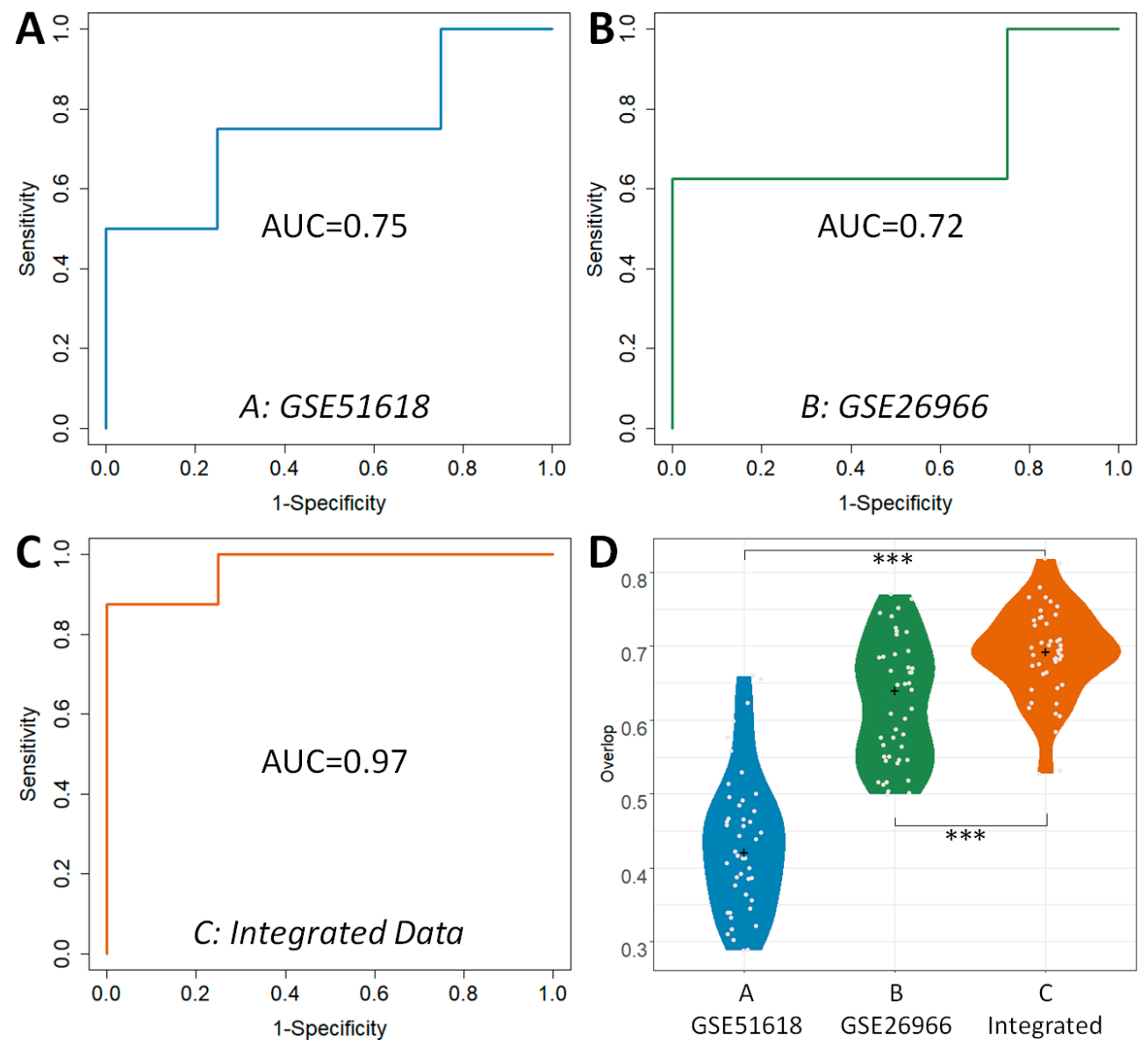

Figure 2. Classification capacity (assessed by AUC (area under the curve)) and robustness (evaluated by Overlap value) of three classifiers. Classifiers were build using (A) GSE51618, (B) GSE26966, and (C) combination of GSE22812, GSE26966, GSE4237, GSE46311, and GSE51618. Statistical comparative analyses of the overlap values among the strategies based on these three datasets were also provided (D). The + presents the median of all overlap values, and ${ }^{* * *}$ presents the $p$ value $<0.001$. 


\subsection{Comparative Analysis on the Robustness of the DEGs Identified by Different Analytical Strategies}

Apart from prediction capacity simultaneously assessed by classification correctness and prediction stability, the robustness of identified DEGs was widely accepted as an additional key metric with its underlying theory distinct from that of prediction ability [69,74]. So far, overlap value had been recognized as the quantitative measure of the robustness of identified DEGs [75]. The higher overlap values represented the more robust DEGs identified by a given strategy. Herein, one sub-dataset was first generated by randomly selecting $2 / 3$ of both cases and controls in the studied dataset, and ten iterations of the same procedure generated ten sub-datasets. For each sub-dataset, a list of DEGs were then identified by LMEB method (fold change $>1.5$ and adjusted $p$-value $<0.05$ ), and the value of overlap between any two sub-datasets was calculated using their corresponding lists of DEGs. In total, there were $45\left(C_{10}^{2}\right)$ overlap values denoting all possible combinations between any two sub-datasets. Finally, overlap values of three different analytical strategies were compared. As shown in the upper section of Table 3, the total numbers of DEGs identified by ten sub-datasets together with the median values of overlap were provided. It was obvious that the total numbers of identified DEGs among ten sub-datasets varied significantly (from 370 to 1310). The median overlap of DDI strategy (0.69) was found larger than that of the other strategies ( 0.64 and 0.42 , respectively).

Table 3. The robustness of the identified markers assessed by 10 random sampling datasets.

\begin{tabular}{ccccc}
\hline Dataset & & A: GSE51618 & B: GSE26966 & C: DDI Strategy \\
\hline Overlap Median across 10 Samplings & 0.42 & 0.64 & 0.69 \\
\hline & 1 & 230 & 244 & 175 \\
& 2 & 149 & 312 & 147 \\
No. of DEGs Identified by the $n$th & 3 & 179 & 332 & 140 \\
Sampling Dataset $(n=)$ & 5 & 319 & 262 & 134 \\
& 6 & 284 & 328 & 132 \\
& 7 & 361 & 349 & 282 \\
& 8 & 283 & 278 & 171 \\
& 9 & 377 & 295 & 172 \\
No. of DEGs Identified & 10 & 585 & 243 & 192 \\
\hline & 10 & $56(0.04)$ & $52(0.14)$ & $71(0.17)$ \\
No. (Percent) of DEGs Co-discovered & $\geq 9$ & $73(0.06)$ & $63(0.17)$ & $90(0.22)$ \\
by N Sampling Datasets & $\geq 8$ & $87(0.07)$ & $75(0.20)$ & $107(0.26)$ \\
& $\geq 7$ & $103(0.08)$ & $87(0.24)$ & $119(0.29)$ \\
& $\geq 6$ & $129(0.10)$ & $104(0.28)$ & $133(0.32)$ \\
\hline
\end{tabular}

Compared with the median value of overlap, the statistical difference of 45 overlap values between different analytical strategies was more meaningful to reveal their level of robustness. Therefore, the comprehensive statistical comparison of robustness among strategies was conducted and illustrated in Figure 2D. Overlap values of three strategies were colored in blue, green and orange. Apart from the enhanced median value of overlap by DDI strategy, all overlap values of DDI strategy were found significantly higher $(p$-value $<0.05)$ than that of the other two. Particularly, as illustrated in Figure 2D, the statistical differences between DDI strategy and others ( $p$-value) were all lower than $1.00 \times 10^{-3}$ $\left(1.89 \times 10^{-24}\right.$ between A and C; $5.56 \times 10^{-5}$ between B and C). Moreover, the majority of the overlap values of DDI strategy were larger than 0.6 , while that of the other strategies were lower than 0.6 . This finding indicated that the DDI strategy performed better than others in the robustness of the identified DEGs. Additionally, Table 3 (lower section) provided the numbers and percentages of DEGs simultaneously discovered by $\mathrm{N}(\mathrm{N} \geq 6, \geq 7, \geq 8, \geq 9,=10)$ sub-datasets. It was very clearly that the robustness of the DEGs identified by DDI strategy was much better than other two strategies in terms of both the number and percentage of co-identified DEGs. Particularly, about one third of the DEGs of 
DDI strategy were identified by over five sub-datasets, which was substantially higher than that of other two ( $28 \%$ and $10 \%$, respectively). $17 \%$ of the DEGs of DDI strategy could be identified by all sub-datasets, which was still significantly higher than that of other two $(14 \%$ and $4 \%$, respectively).

\subsection{Annotating the Immune-Related DEGs and Candidate Target Discovery for PA Immunotherapy}

The discussion above testified the effectiveness of the adopted feature selection algorithm and revealed the superior robustness and classification ability of the proposed DDI strategy compared with that based on the single dataset. To maximumly enhance the prediction power of constructed model, the most comprehensive set of PA-related microarray data were collected (Table 1) and integrated to form data $\mathbf{D}$ (Figure 1). To the best of our knowledge, the dataset $\mathbf{D}$ was the largest one among current PA-related transcriptomic analyses. Using LMEB method (fold change $>1.5$ and adjusted $p$-value $<0.05$ ), a total of 370 DEGs were discovered. As shown in Table 4, the top-ranked DEGs (top-20 for up-regulation \& another top-20 for down-regulation) were provided, and the identified DEGs that could not be found by the other two strategies were highlighted in bold font. These top-ranked DEGs and their relevance to PAs were reviewed by comprehensive literature review, and a variety of DEGs were identified as relevant to PAs by experiments. For example, the mRNA expression of TSHB was found to be absent in most PA patients [76]. Different from normal pituitary, the GAL was reported to be rarely expressed in somatotroph adenoma and prolactinoma [77]. The expression of GAL was substantially suppressed in the tissue of PA patients compared with that in healthy pituitary [47]. The CEL was identified to regulate the hormone secretion in adenomatous pituitary cells [78]. The high expression of PRL and under-expression of RPS29 were observed in pituitary adenomas [79]. The c-Fos overexpression was found to be much less common in pituitary tumors and did not necessarily correlate with the ability of tumor to become invasive [80]. Pathway analysis facilitated the discovery of PMAIP1 as important in the tumorigenesis and progression of PAs [81]. The serum AGR2 level was significantly higher in the serum of PA patients than the patients with other sellar lesions, which suggests $A G R 2$ a potential marker for PAs' diagnosis [82]. By annotating those 370 DEGs using GO terms, 66 (17.8\%) DEGs were discovered as closely immune-related. Table 5 provided a full list of the immune-related DEGs together with their fold changes and $p$-values. Due to their close relationship with human immune system and the differential expression between PA patients and healthy individuals, they are potential target candidates for PA immunotherapy.

Table 4. Top 20 up- and downregulated DEGs identified by combining all seven datasets in Table 1. These DEGs that could not be identified by both GSE62966 and GSE51618 dataset were highlighted in bold font.

\begin{tabular}{ccccccc}
\hline No. & Entrez & Symbol & LogFC & $p$-Value & GES62966 & GSE51618 \\
\hline 1 & 5443 & POMC & -3.85 & $2.79 \times 10^{-18}$ & -8.00 & -7.09 \\
2 & 7252 & TSHB & -3.26 & $6.65 \times 10^{-16}$ & -5.96 & -8.07 \\
3 & 51,083 & GAL & -2.69 & $4.22 \times 10^{-21}$ & -5.10 & -8.03 \\
4 & 1056 & CEL & -2.22 & $9.21 \times 10^{-10}$ & -5.73 & -2.23 \\
5 & 3240 & $H P$ & -2.21 & $1.06 \times 10^{-9}$ & -4.10 & - \\
6 & 3397 & ID1 & -2.08 & $3.85 \times 10^{-16}$ & -3.10 & -3.84 \\
7 & 5446 & PON3 & -2.00 & $2.01 \times 10^{-7}$ & -3.46 & - \\
8 & 5617 & PRL & -1.93 & $6.41 \times 10^{-3}$ & -7.33 & - \\
9 & 1410 & CRYAB & -1.88 & $1.31 \times 10^{-12}$ & -2.57 & - \\
10 & 4885 & NPTX2 & -1.87 & $8.75 \times 10^{-9}$ & -4.18 & - \\
$\mathbf{1 1}$ & $\mathbf{6 1 6 1}$ & RPL32 & $-\mathbf{1 . 8 3}$ & $\mathbf{1 . 0 5} \times \mathbf{1 0}^{-2}$ & - & - \\
12 & 4821 & NKX2-2 & -1.82 & $3.36 \times 10^{-7}$ & -6.26 & -0.83 \\
13 & 2697 & GJA1 & -1.64 & $5.94 \times 10^{-8}$ & -3.73 & - \\
14 & 5105 & PCK1 & -1.61 & $1.74 \times 10^{-5}$ & -6.43 & -2.38 \\
$\mathbf{1 5}$ & $\mathbf{6 2 3 5}$ & RPS29 & $-\mathbf{1 . 5 4}$ & $\mathbf{1 . 1 8} \times \mathbf{1 0}^{-2}$ & - & - \\
16 & 12 & SERPINA3 & -1.48 & $4.62 \times 10^{-4}$ & -4.15 & - \\
17 & 2353 & FOS & -1.45 & $2.85 \times 10^{-7}$ & -3.80 & - \\
\hline
\end{tabular}


Table 4. Cont

\begin{tabular}{|c|c|c|c|c|c|c|}
\hline No. & Entrez & Symbol & $\operatorname{LogFC}$ & $p$-Value & GES62966 & GSE51618 \\
\hline 18 & 5366 & PMAIP1 & -1.44 & $4.11 \times 10^{-7}$ & -3.85 & -2.39 \\
\hline 19 & 6146 & RPL22 & -1.42 & $2.91 \times 10^{-2}$ & - & - \\
\hline 20 & 10,551 & AGR2 & -1.41 & $5.24 \times 10^{-5}$ & -2.47 & -3.75 \\
\hline 21 & 22,999 & RIMS1 & 0.78 & $3.05 \times 10^{-2}$ & - & - \\
\hline 22 & 8573 & CASK & 0.78 & $5.10 \times 10^{-6}$ & 0.85 & 1.48 \\
\hline 23 & 5795 & PTPRJ & 0.78 & $1.01 \times 10^{-2}$ & - & - \\
\hline 24 & 1272 & CNTN1 & 0.80 & $7.88 \times 10^{-5}$ & 1.70 & - \\
\hline 25 & 22,858 & ICK & 0.81 & $1.53 \times 10^{-2}$ & - & - \\
\hline 26 & 23,390 & ZDHНC17 & 0.81 & $4.94 \times 10^{-3}$ & - & - \\
\hline 27 & 51,755 & CDK12 & 0.81 & $3.45 \times 10^{-2}$ & - & - \\
\hline 28 & 4684 & NCAM1 & 0.81 & $5.74 \times 10^{-3}$ & 0.74 & - \\
\hline 29 & 4863 & NPAT & 0.81 & $1.07 \times 10^{-2}$ & - & - \\
\hline 30 & 57,125 & PLXDC1 & 0.82 & $6.76 \times 10^{-4}$ & 0.76 & - \\
\hline 31 & 9472 & $A K A P 6$ & 0.83 & $1.75 \times 10^{-3}$ & 0.86 & - \\
\hline 32 & 23,101 & MCF2L2 & 0.83 & $2.02 \times 10^{-2}$ & - & - \\
\hline 33 & 868 & $C B L B$ & 0.84 & $3.45 \times 10^{-2}$ & - & - \\
\hline 34 & 8490 & RGS5 & 0.84 & $3.25 \times 10^{-4}$ & 1.41 & - \\
\hline 35 & 1006 & $\mathrm{CDH8}$ & 0.85 & $2.18 \times 10^{-3}$ & 2.94 & - \\
\hline 36 & 55,752 & SEPT11 & 0.87 & $1.13 \times 10^{-2}$ & - & - \\
\hline 37 & 5149 & PDE6H & 0.89 & $1.67 \times 10^{-2}$ & 1.36 & - \\
\hline 38 & 1641 & $D C X$ & 0.91 & $6.76 \times 10^{-4}$ & 3.14 & - \\
\hline 39 & 29,899 & GPSM2 & 0.91 & $1.73 \times 10^{-2}$ & 1.04 & - \\
\hline 40 & 23,305 & ACSL6 & 0.91 & $3.51 \times 10^{-3}$ & 0.90 & - \\
\hline
\end{tabular}

Table 5. Immune-related DEGs identified in this study with fold change, $p$-value, and their representative biological processes and molecular functions.

\begin{tabular}{|c|c|c|c|c|}
\hline Entrez ID & Gene Symbol & $\operatorname{LogFC}$ & $p$-Value & $\begin{array}{c}\text { Representative GO Biological Processes and } \\
\text { Molecular Functions }\end{array}$ \\
\hline 51,083 & GAL & -2.69 & $4.22 \times 10^{-21}$ & $\begin{array}{l}\text { negative regulation of immune system process; regulation of } \\
\text { immune process }\end{array}$ \\
\hline 3240 & $H P$ & -2.21 & $1.06 \times 10^{-9}$ & immune system process \\
\hline 2353 & FOS & -1.45 & $2.85 \times 10^{-7}$ & $\begin{array}{l}\text { positive regulation of immune system process; regulation of } \\
\text { immune response }\end{array}$ \\
\hline 5366 & PMAIP1 & -1.44 & $4.11 \times 10^{-7}$ & immune effector process; immune system process \\
\hline 6146 & RPL22 & -1.42 & $2.91 \times 10^{-2}$ & immune system development; immune system process \\
\hline 7060 & THBS4 & -1.33 & $7.19 \times 10^{-6}$ & $\begin{array}{l}\text { positive regulation of immune system process; regulation of } \\
\text { immune process }\end{array}$ \\
\hline 10,410 & IFITM3 & -1.28 & $8.39 \times 10^{-6}$ & $\begin{array}{l}\text { innate immune response; immune effector process; immune } \\
\text { system process }\end{array}$ \\
\hline 2488 & FSHB & -1.28 & $5.95 \times 10^{-3}$ & regulation of immune system process \\
\hline 133 & $A D M$ & -1.28 & $4.34 \times 10^{-7}$ & $\begin{array}{l}\text { humoral immune response; immune response; immune } \\
\text { system process }\end{array}$ \\
\hline 2719 & GPC3 & -1.22 & $3.09 \times 10^{-9}$ & immune system development; immune system process \\
\hline 7852 & CXCR4 & -1.22 & $3.24 \times 10^{-9}$ & immune system process \\
\hline 347 & $A P O D$ & -1.21 & $2.78 \times 10^{-5}$ & $\begin{array}{l}\text { negative regulation of immune system process; regulation of } \\
\text { immune process }\end{array}$ \\
\hline 9353 & SLIT2 & -1.21 & $6.81 \times 10^{-10}$ & $\begin{array}{l}\text { negative regulation of immune system process; regulation of } \\
\text { immune process }\end{array}$ \\
\hline 8324 & FZD7 & -1.21 & $1.74 \times 10^{-8}$ & immune system development; immune system process \\
\hline 2197 & $F A U$ & -1.19 & $1.35 \times 10^{-2}$ & humoral immune response; innate immune response in mucosa \\
\hline 4783 & NFIL3 & -1.14 & $8.44 \times 10^{-5}$ & immune response; immune system process \\
\hline 6218 & RPS17 & -1.13 & $2.70 \times 10^{-2}$ & immune system process \\
\hline
\end{tabular}


Table 5. Cont

\begin{tabular}{|c|c|c|c|c|}
\hline Entrez ID & Gene Symbol & $\operatorname{LogFC}$ & $p$-Value & $\begin{array}{c}\text { Representative GO Biological Processes and } \\
\text { Molecular Functions }\end{array}$ \\
\hline 5950 & RBP4 & -1.08 & $1.79 \times 10^{-2}$ & $\begin{array}{l}\text { positive regulation of production of molecular mediator of } \\
\text { immune response }\end{array}$ \\
\hline 5919 & RARRES2 & -1.06 & $4.34 \times 10^{-7}$ & $\begin{array}{l}\text { positive regulation of immune system process; regulation of } \\
\text { immune process }\end{array}$ \\
\hline 3669 & ISG20 & -1.03 & $8.23 \times 10^{-8}$ & $\begin{array}{c}\text { innate immune response; immune effector process; immune } \\
\text { system process }\end{array}$ \\
\hline 3059 & HCLS1 & -1.02 & $6.70 \times 10^{-5}$ & $\begin{array}{l}\text { positive regulation of immune system process; regulation of } \\
\text { immune process }\end{array}$ \\
\hline 6279 & $S 100 A 8$ & -1.01 & $1.99 \times 10^{-3}$ & $\begin{array}{l}\text { innate immune response; immune response; immune } \\
\text { system process }\end{array}$ \\
\hline 710 & SERPING1 & -1.00 & $6.70 \times 10^{-6}$ & $\begin{array}{l}\text { adaptive immune response; b cell mediated immunity; humoral } \\
\text { immune response }\end{array}$ \\
\hline 716 & C1S & -1.00 & $5.90 \times 10^{-4}$ & $\begin{array}{l}\text { adaptive/innate immune response; Leukocyte } \\
\text { mediated immunity }\end{array}$ \\
\hline 7056 & THBD & -1.00 & $2.52 \times 10^{-6}$ & immune system process \\
\hline 715 & $C 1 R$ & -0.98 & $3.31 \times 10^{-6}$ & $\begin{array}{c}\text { adaptive/innate immune response; positive regulation of } \\
\text { immune system process }\end{array}$ \\
\hline 1672 & DEFB1 & -0.92 & $1.44 \times 10^{-4}$ & humoral immune response; innate immune response in mucosa \\
\hline 2669 & GEM & -0.89 & $2.22 \times 10^{-4}$ & immune response; immune system process \\
\hline 1958 & EGR1 & -0.86 & $2.45 \times 10^{-3}$ & $\begin{array}{c}\text { innate immune response; immune response; immune } \\
\text { system development }\end{array}$ \\
\hline 6662 & SOX9 & -0.86 & $3.43 \times 10^{-4}$ & $\begin{array}{l}\text { negative regulation of immune system process; regulation of } \\
\text { immune process }\end{array}$ \\
\hline 3426 & CFI & -0.84 & $6.05 \times 10^{-10}$ & $\begin{array}{c}\text { adaptive immune response; leukocyte/lymphocyte } \\
\text { mediated immunity }\end{array}$ \\
\hline 7412 & VCAM1 & -0.84 & $6.87 \times 10^{-7}$ & $\begin{array}{c}\text { innate immune response; positive regulation of immune } \\
\text { system process }\end{array}$ \\
\hline 1366 & CLDN7 & -0.84 & $4.27 \times 10^{-3}$ & $\begin{array}{l}\text { regulation of immune effector process; regulation of immune } \\
\text { system process }\end{array}$ \\
\hline 3726 & $J U N B$ & -0.84 & $2.43 \times 10^{-5}$ & immune system development; immune system process \\
\hline 9796 & PHYHIP & -0.82 & $2.78 \times 10^{-3}$ & $\begin{array}{c}\text { regulation of immune effector process; regulation of immune } \\
\text { system process }\end{array}$ \\
\hline 7049 & TGFBR3 & -0.81 & $3.58 \times 10^{-3}$ & $\begin{array}{l}\text { immune response; immune system development; immune } \\
\text { system process }\end{array}$ \\
\hline 3958 & LGALS3 & -0.80 & $4.63 \times 10^{-2}$ & $\begin{array}{c}\text { innate immune response; negative regulation of immune } \\
\text { effector process }\end{array}$ \\
\hline 3485 & IGFBP2 & -0.78 & $1.23 \times 10^{-3}$ & $\begin{array}{l}\text { positive regulation of immune system process; regulation of } \\
\text { immune process }\end{array}$ \\
\hline 1051 & CEBPB & -0.75 & $2.38 \times 10^{-3}$ & $\begin{array}{l}\text { negative regulation of immune system process; regulation of } \\
\text { immune process }\end{array}$ \\
\hline 302 & ANXA2 & -0.72 & $1.55 \times 10^{-2}$ & immune system development; immune system process \\
\hline 5806 & PTX3 & -0.72 & $2.46 \times 10^{-3}$ & $\begin{array}{l}\text { innate immune response; immune effector process; immune } \\
\text { system process }\end{array}$ \\
\hline 3320 & HSP90AA1 & -0.71 & $1.90 \times 10^{-2}$ & $\begin{array}{l}\text { positive regulation of immune system process; activation of } \\
\text { immune response }\end{array}$ \\
\hline 7704 & ZBTB16 & -0.69 & $3.81 \times 10^{-2}$ & negative/positive regulation of immune system process \\
\hline 8543 & LMO4 & -0.69 & $1.35 \times 10^{-2}$ & immune system development; immune system process \\
\hline 6223 & RPS19 & -0.69 & $1.25 \times 10^{-2}$ & $\begin{array}{c}\text { regulation of innate immune response; immune } \\
\text { system development }\end{array}$ \\
\hline 4057 & LTF & -0.68 & $3.41 \times 10^{-2}$ & humoral immune response; innate immune response in mucosa \\
\hline $100,133,941$ & $C D 24$ & -0.65 & $5.68 \times 10^{-3}$ & $\begin{array}{l}\text { positive regulation of immune system process; immune } \\
\text { system process }\end{array}$ \\
\hline 684 & BST2 & -0.64 & $8.65 \times 10^{-3}$ & $\begin{array}{c}\text { humoral/innate immune response; negative regulation of } \\
\text { immune response }\end{array}$ \\
\hline 23,543 & RBFOX2 & 0.59 & $5.42 \times 10^{-3}$ & regulation of immune system process \\
\hline
\end{tabular}


Table 5. Cont.

\begin{tabular}{ccccc}
\hline Entrez ID & Gene Symbol & LogFC & $p$-Value & $\begin{array}{c}\text { Representative GO Biological Processes and } \\
\text { Molecular Functions }\end{array}$ \\
\hline 5747 & PTK2 & 0.59 & $1.12 \times 10^{-2}$ & $\begin{array}{c}\text { activation of immune response; positive regulation of } \\
\text { immune response }\end{array}$ \\
\hline 2047 & EPHB1 & 0.60 & $8.01 \times 10^{-3}$ & immune system process; immunological synapse formation \\
\hline 27,242 & TNFRSF21 & 0.60 & $4.66 \times 10^{-3}$ & $\begin{array}{c}\text { adaptive/humoral immune response; negative regulation of } \\
\text { immune process }\end{array}$ \\
\hline 8754 & ADAM9 & 0.61 & $1.68 \times 10^{-2}$ & immune system process \\
\hline 3175 & ONECUT1 & 0.64 & $1.36 \times 10^{-3}$ & immune system development; immune system process \\
\hline 54,861 & SNRK & 0.64 & $1.61 \times 10^{-2}$ & immune system development; immune system process \\
\hline 801 & CALM1 & 0.64 & $6.76 \times 10^{-4}$ & immune response regulating cell surface receptor \\
signaling pathway
\end{tabular}

The human protein-protein interaction (PPI) network analyses (Figure 3) further revealed relations among the identified DEGs and immune-related ones (highlighted in blue). Among the identified target candidates for PA immunotherapy, MAPK1, FOS and HSP90AA1 were the top three immuno-candidates with the highest connectivity (network degree) to other human proteins. Moreover, galanin (GAL) was identified as greatly downregulated DEGs in the pituitary glands of PA patients. Due to it immunomodulatory property in PA, the GAL could be expected as a promising target candidate for PA immunotherapy, and this finding was in accordance to previous work [47]. The dysregulation of LMO4 was identified in this study, which induced STAT3 activation in brain [83] and subsequently regulated the expression of programmed death-ligand 1 (PD-L1) [84]. Since the upregulated expression of immunosuppressive protein $P D-L 1$ was observed in the pituitary gland of PA patients [43], the inhibition of LMO4/STAT3/PD-L1 signaling could block the immune evasion by recovering the recognition and elimination of cancer cells via $\mathrm{CD} 8^{+}$lymphocytes [48]. Furthermore, the transforming growth factor-beta (TGFB) was reported to be one of the chief immune suppressive mediators of PRL secretion and PA proliferation [49,50]. Its receptor, TGFBR3, was also discovered in this study as a DEG, which could be another target candidate for developing novel PA immunotherapy. 


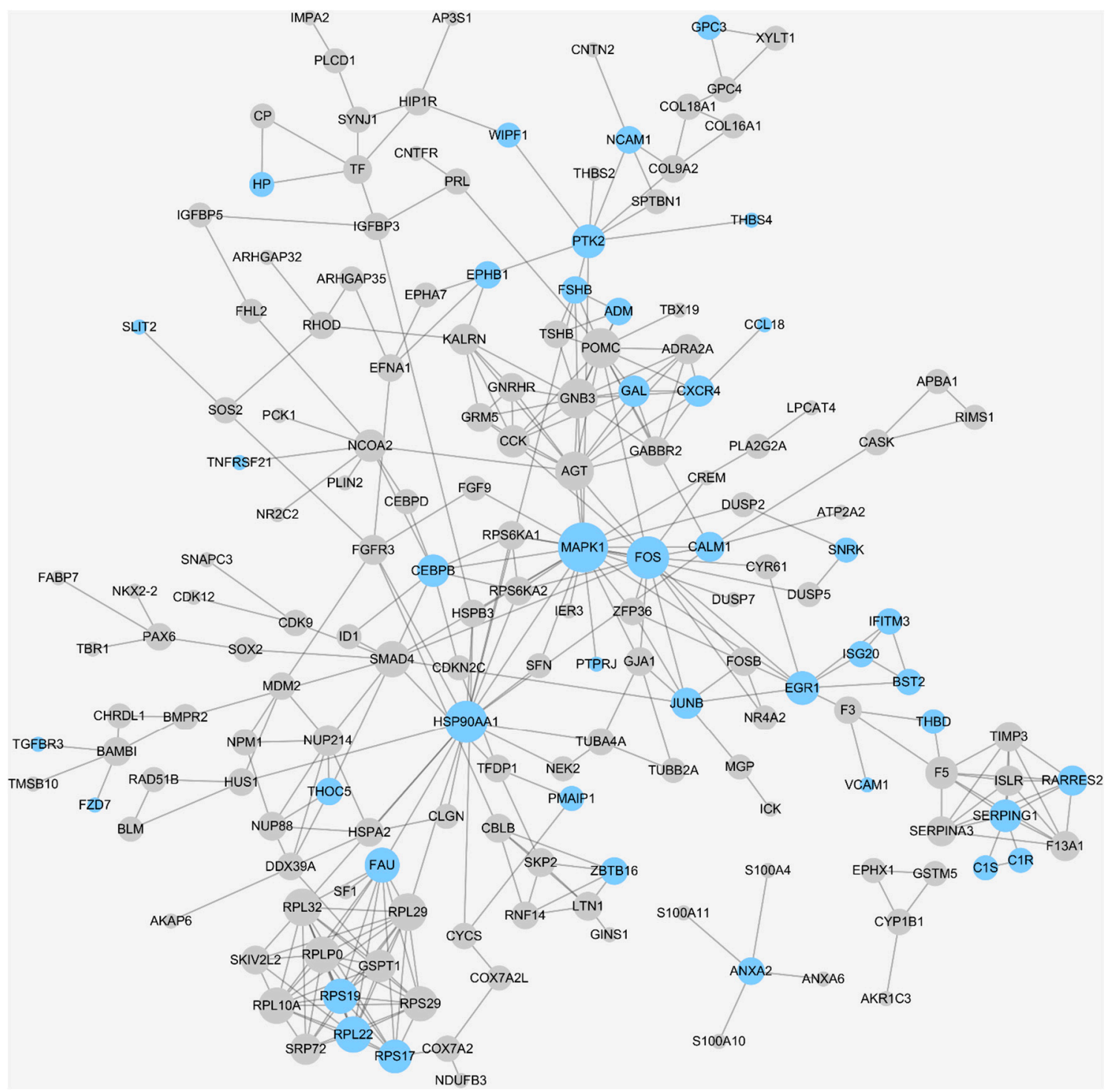

Figure 3. Human protein-protein interaction (PPI) network constructed based on 370 DEGs identified in this study. The PPI information was collected from the 2017 version of the STRING database and visualized using the Cytoscape software package. The diameter of each protein was defined by its network degree, and the proteins colored in blue were identified to be "immune-related" in this study.

\section{Materials and Methods}

\subsection{Construction of Analytical Datasets and Discovery of Differentially Expressed Genes}

Pituitary glands were wildly recognized as the major locus of PA's dysfunction [63]. In this study, a variety of microarray studies based on the tissues of pituitary gland were thus collected through searching "pituitary adenoma", "pituitary tumor", "pituitary neoplasm", "pituitary macroadenoma", "pituitary carcinoma", and "pituitary cancer" in the Gene Expression Omnibus (GEO) [85]. As a result, seven independent microarray studies were collected. As shown in Table 1, each dataset comprises a cohort of PA patients and/or another cohort of healthy controls. Among these studies, a limited number of both diseased and healthy samples were reported ( 4-16 samples for the PA patients and $\sim 0-9$ samples for healthy people). In this study, four analytical datasets were constructed for (1) evaluating the effectiveness of the adopted feature selection algorithm, (2) conducting a performance comparison between the DDI strategy and the strategy of a single dataset, and (3) constructing the final model for identifying the immune-related molecule underlying PA's development. 
In particular, the four analytical datasets included (as illustrated in Figure 1 and Table 1): (A) GSE51618, (B) GSE26966, (C) DDI of five datasets, and (D) DDI of seven datasets. Datasets (A-C) were used for validating feature selection method and comparing the performances of DDI strategy and the strategy of single dataset, and dataset $\mathrm{D}$ was applied to identify the target candidates for the immunotherapy of PA.

The direct data integration (DDI) strategy combining multiple datasets was carried out in the $R$ environment (available online: http:/ / www.r-project.org). The raw data (the CEL file) was first read, log transformed, and normalized, and all parameters were set as default. Then, outliers in each dataset were checked and removed, and all probe sets were mapped to their corresponding genes by Bioconductor [86]. Average expression value was retained if one gene was mapped to multiple probes. To remove the batch effect among datasets, $Z$ score transformation [87-89] (provided in Equation (1)) was used to adjust the gene expression levels in each dataset.

$$
\mathrm{Z} \text { score }=\frac{x_{i}-\bar{x}}{\delta}
$$

where $x_{i}$ refers to the raw intensity of each gene, $\bar{x}$ indicates the average intensity of all genes within single experiment and $\delta$ represents the standard deviation (SD) of all expression intensities in one array. After this process, the mean $\mathrm{Z}$ score for each array became zero with SD equaling one. The DDI strategy was applied to construct the dataset C (integrating GSE22812, GSE26966, GSE4237, GSE46311, and GSE51618) and D (integrating GSE2175, GSE22812, GSE26966, GSE36314, GSE4237, GSE46311, and GSE51618). As a result, the dataset $C$ contained 60 PA patients and 12 healthy people, and dataset D contained 68 PA patients and 16 healthy individuals (Figure 1). The differentially expressed genes (DEGs) between the PA patients and healthy individuals were identified using the linear models and empirical Bayes (LMEB) [90] by the $R$ package limma [91]. Herein, the genes with fold change $>1.5$ and adjusted $p$-value $<0.05$ were identified as the differentially expressed genes between case and control samples (Figure 1).

\subsection{Validation of the Constructed Prediction Models Based on Different Analytical Datasets}

A systematic validation and comparison of the prediction models constructed based on three analytical datasets (A-C) was conducted by evaluating the relevance level to PAs of the identified DEGs and by assessing the robustness of marker discovery and the classification ability of the constructed models.

\subsubsection{The Level of Relevance of the Identified DEGs to Pituitary Adenoma}

For complex disorders like PA, the identified DEGs are expected to contain a substantial percentage of PA-related genes [92], and a certain number of irrelevant genes may be inevitably selected due to measurement variability. Herein, a comprehensive literature review was performed to investigate the PA relevance of the top-ranked DEGs. Moreover, the pathway enrichment analyses on the identified DEGs were also conducted to identify the significantly overrepresented KEGG pathways using hypergeometric tests (adjusted $p$-value <0.05) [93]. According to another comprehensive literature review on the top-ranked pathways playing key roles in PA, the level of PA relevance of the pathways enriched by three different strategies were compared. Finally, the gene ontology (GO) enrichment analyses using biological process (BP) and molecular function (MF) by the identified DEGs were conducted to identify the significantly overrepresented GO terms using hypergeometric tests (adjusted $p$-value < 0.05) [93]. The level of PA relevance of the top-ranked GO terms was also reviewed, analyzed, and compared among three different strategies. 
3.2.2. The Classification Capacity of the Identified DEGs Assessed by the Independent Validation Dataset

The classification abilities of the DEGs identified by three different strategies (Dataset A, B and C shown in Figure 1) were assessed and compared by predicting PA outcomes of the independent validation dataset containing eight PA patients and four healthy controls. To statistically maximize both the prediction power of the constructed models and the validation effectiveness, the independent validation dataset was constructed by two datasets with the smallest amount of case and control samples: GSE2175 (four cases and one control) and GSE36314 (four cases and three controls). The classification models were constructed by the classifier of support vector machine (SVM) [94]. A variety of popular assessment metrics were adopted, which included true positive $(T P)$, true negative $(T N)$, false positive $(F P)$, false negative $(F N)$, accuracy $(A C C)$, sensitivity $(S E N)$, specificity $(S P E)$, Matthews correlation coefficient $(M C C)$, receiver operating characteristics (ROC) curve, and the area under ROC curve $(A U C)$. All these metrics were frequently used in current Omics researches [95-98].

\subsubsection{The Robustness of the Identified DEGs among Different Sampling Groups}

The robustness of the identified DEGs among different samplings groups was widely accepted to be another metric for assessing the constructed prediction models [69]. Particularly, overlap value between two sampling groups was applied to quantify the robustness of the identified DEGs [75]. In this study, a sub-dataset was first generated by randomly selecting $2 / 3$ samples of the original dataset, and ten iterations of this selection procedure resulted in ten sub-datasets. For each sub-dataset, a list of DEGs were identified by LMEB (fold change $>1.5$ and adjusted $p$-value $<0.05$ ), and the overlap value between any two sub-datasets was calculated using their corresponding lists of DEGs identified. In total, there were $45\left(C_{10}^{2}\right)$ overlap values denoting all possible combinations between any two sub-datasets. Finally, the overlap values of three different strategies were compared to assess their robustness of the identified DEGs.

\subsection{Annotating the Immune-Related DEGs and Candidate Target Discovery for PA Immunotherapy}

Due to the substantially enhanced robustness and classification capacity of the DDI strategy discovered in this study, the DDI of all seven datasets (Table 1) was conducted to achieve the most comprehensive discovery of DEG between patients and healthy individuals. The method applied for data integration and batch effects removal was shown in the first section of Materials and Methods section. The samples integrated in constructing the final prediction model included 68 PA patients and 16 healthy individuals. To the best of our knowledge, this newly integrated dataset is the largest one among the current PA-related transcriptomic analyses. Based on the comprehensive dataset D integrated above (Figure 1), DEGs were further identified using the LMEB method (fold change $>1.5$ and adjusted $p$-value $<0.05)$. Then, GO terms were used to annotate and identify immune-related DEGs. Moreover, the human protein-protein interaction (PPI) network analysis was introduced to explore the connection among identified DEGs [99]. In particular, the STRING database [100] was adopted to the construct human PPI network, and only PPI data of high confidence levels $(>0.7)$ were applied in this study. The identified DEGs together with the STRING human PPI network were input into Cytoscape [101] for visualization, and only the identified DEGs were displayed (round circles). The immune-related DEGs annotated by GO terms were colored by light blue.

\section{Conclusions}

In this study, the direct data integration strategy was proposed, and its classification ability and robustness were assessed in this study. Compared with the traditional strategy based on a single dataset, the DDI strategy was found to greatly enhance the robustness of identified DEGs, which may be attributed to the significant enlargement of the sample size. Based on the comprehensive analysis of the available PA-related transcriptomics data, 370 DEGs were identified, and 66 immune-related DEGs were annotated and proposed as target candidates for PA immunotherapy. Using the PPI network 
analysis and literature review, several promising candidate targets (GAL, LMO4, STAT3, PD-L1, TGFB and TGFBR3) were further proposed for PA immunotherapy.

Supplementary Materials: The following are available online at http:/ / www.mdpi.com/1422-0067/20/1/151/ s1.

Author Contributions: F.Z. conceived the idea and supervised the work. Q.Y. collected the multiple datasets and completed data integration. Q.Y., Y.W., S.Z. and J.T. performed research and developed the tool. Q.Y., F.L., J.Y., Y.L. (Yi Li) and W.W.X. wrote the original scripts and performed analysis. J.F., B.L. and Y.L. (Yongchao Luo) finished the visualization of data, and F.Z. performed writing-review and editing of the manuscript. All authors reviewed and approved the final version of the manuscript.

Acknowledgments: This research was funded by the National Natural Science Foundation of China (81872798), the National Key Research and Development Program of China (2018YFC0910500), Innovation Project on Industrial Generic Key Technologies of Chongqing (cstc2015zdcy-ztzx120003), and Fundamental Research Funds for the Central Universities (2018QNA7023, 10611CDJXZ238826, 2018CDQYSG0007, CDJZR14468801, CDJKXB14011).

Conflicts of Interest: The authors declare no conflicts of interest.

\section{References}

1. Salomon, M.P.; Wang, X.; Marzese, D.M.; Hsu, S.C.; Nelson, N.; Zhang, X.; Matsuba, C.; Takasumi, Y.; Ballesteros-Merino, C.; Fox, B.A.; et al. The epigenomic landscape of pituitary adenomas reveals specific alterations and differentiates among acromegaly, cushing's disease and endocrine-inactive subtypes. Clin. Cancer Res. 2018, 24, 4126-4136. [CrossRef] [PubMed]

2. Zhu, H.; Guo, J.; Shen, Y.; Dong, W.; Gao, H.; Miao, Y.; Li, C.; Zhang, Y. Functions and mechanisms of tumor necrosis factor-alpha and noncoding rnas in bone-invasive pituitary adenomas. Clin. Cancer Res. 2018, 24, 5757-5766. [CrossRef] [PubMed]

3. Tu, G.; Fu, T.; Yang, F.; Yao, L.; Xue, W.; Zhu, F. Prediction of glun2b-ct1290-1310/dapk1 interaction by protein(-)peptide docking and molecular dynamics simulation. Molecules 2018, 23, 3018. [CrossRef]

4. Nota, N.M.; Wiepjes, C.M.; de Blok, C.J.M.; Gooren, L.J.G.; Peerdeman, S.M.; Kreukels, B.P.C.; den Heijer, M. The occurrence of benign brain tumours in transgender individuals during cross-sex hormone treatment. Brain 2018, 141, 2047-2054. [CrossRef] [PubMed]

5. Han, Z.J.; Xue, W.W.; Tao, L.; Zhu, F. Identification of novel immune-relevant drug target genes for alzheimer's disease by combining ontology inference with network analysis. CNS Neurosci. Ther. 2018, 24, 1253-1263. [CrossRef] [PubMed]

6. Fu, T.; Zheng, G.; Tu, G.; Yang, F.; Chen, Y.; Yao, X.; Li, X.; Xue, W.; Zhu, F. Exploring the binding mechanism of metabotropic glutamate receptor 5 negative allosteric modulators in clinical trials by molecular dynamics simulations. ACS Chem. Neurosci. 2018, 9, 1492-1502. [CrossRef] [PubMed]

7. Mehta, G.U.; Lonser, R.R. Management of hormone-secreting pituitary adenomas. Neuro. Oncol. 2017, 19, 762-773. [CrossRef]

8. Xue, W.; Yang, F.; Wang, P.; Zheng, G.; Chen, Y.; Yao, X.; Zhu, F. What contributes to serotonin-norepinephrine reuptake inhibitors' dual-targeting mechanism? The key role of transmembrane domain 6 in human serotonin and norepinephrine transporters revealed by molecular dynamics simulation. ACS Chem. Neurosci. 2018, 9, 1128-1140. [CrossRef]

9. Wang, P.; Fu, T.; Zhang, X.; Yang, F.; Zheng, G.; Xue, W.; Chen, Y.; Yao, X.; Zhu, F. Differentiating physicochemical properties between ndris and snris clinically important for the treatment of adhd. Biochim. Biophys. Acta Gen. Subj. 2017, 1861, 2766-2777. [CrossRef]

10. Molitch, M.E. Diagnosis and treatment of pituitary adenomas: A review. JAMA 2017, 317, 516-524. [CrossRef]

11. Castinetti, F.; Regis, J.; Dufour, H.; Brue, T. Role of stereotactic radiosurgery in the management of pituitary adenomas. Nat. Rev. Endocrinol. 2010, 6, 214-223. [CrossRef] [PubMed]

12. Wang, P.; Zhang, X.; Fu, T.; Li, S.; Li, B.; Xue, W.; Yao, X.; Chen, Y.; Zhu, F. Differentiating physicochemical properties between addictive and nonaddictive adhd drugs revealed by molecular dynamics simulation studies. ACS Chem. Neurosci. 2017, 8, 1416-1428. [CrossRef] [PubMed]

13. Yang, F.Y.; Fu, T.T.; Zhang, X.Y.; Hu, J.; Xue, W.W.; Zheng, G.X.; Li, B.; Li, Y.H.; Yao, X.J.; Zhu, F. Comparison of computational model and X-ray crystal structure of human serotonin transporter: Potential application for the pharmacology of human monoamine transporters. Mol. Simul. 2017, 43, 1089-1098. [CrossRef] 
14. Li, Y.H.; Yu, C.Y.; Li, X.X.; Zhang, P.; Tang, J.; Yang, Q.; Fu, T.; Zhang, X.; Cui, X.; Tu, G.; et al. Therapeutic target database update 2018: Enriched resource for facilitating bench-to-clinic research of targeted therapeutics. Nucleic Acids Res. 2018, 46, D1121-D1127. [PubMed]

15. Zhu, F.; Li, X.X.; Yang, S.Y.; Chen, Y.Z. Clinical success of drug targets prospectively predicted by in silico study. Trends Pharmacol. Sci. 2018, 39, 229-231. [CrossRef] [PubMed]

16. Tang, J.; Zhang, Y.; Fu, J.; Wang, Y.; Li, Y.; Yang, Q.; Yao, L.; Xue, W.; Zhu, F. Computational advances in the label-free quantification of cancer proteomics data. Curr. Pharm. Des. 2018. [CrossRef] [PubMed]

17. Frara, S.; Maffezzoni, F.; Mazziotti, G.; Giustina, A. Current and emerging aspects of diabetes mellitus in acromegaly. Trends Endocrinol. Metab. 2016, 27, 470-483. [CrossRef] [PubMed]

18. Zhu, F.; Han, B.; Kumar, P.; Liu, X.; Ma, X.; Wei, X.; Huang, L.; Guo, Y.; Han, L.; Zheng, C.; et al. Update of ttd: Therapeutic target database. Nucleic Acids Res. 2010, 38, D787-D791. [CrossRef]

19. Zheng, G.; Yang, F.; Fu, T.; Tu, G.; Chen, Y.; Yao, X.; Xue, W.; Zhu, F. Computational characterization of the selective inhibition of human norepinephrine and serotonin transporters by an escitalopram scaffold. Phys. Chem. Chem. Phys. 2018, 20, 29513-29527. [CrossRef]

20. Li, X.X.; Yin, J.; Tang, J.; Li, Y.; Yang, Q.; Xiao, Z.; Zhang, R.; Wang, Y.; Hong, J.; Tao, L.; et al. Determining the balance between drug efficacy and safety by the network and biological system profile of its therapeutic target. Front. Pharmacol. 2018, 9, 1245. [CrossRef]

21. Losa, M.; Bogazzi, F.; Cannavo, S.; Ceccato, F.; Curto, L.; De Marinis, L.; Iacovazzo, D.; Lombardi, G.; Mantovani, G.; Mazza, E.; et al. Temozolomide therapy in patients with aggressive pituitary adenomas or carcinomas. J. Neurooncol. 2016, 126, 519-525. [CrossRef] [PubMed]

22. Yang, H.; Qin, C.; Li, Y.H.; Tao, L.; Zhou, J.; Yu, C.Y.; Xu, F.; Chen, Z.; Zhu, F.; Chen, Y.Z. Therapeutic target database update 2016: Enriched resource for bench to clinical drug target and targeted pathway information. Nucleic Acids Res. 2016, 44, D1069-D1074. [CrossRef] [PubMed]

23. Zhu, F.; Shi, Z.; Qin, C.; Tao, L.; Liu, X.; Xu, F.; Zhang, L.; Song, Y.; Liu, X.; Zhang, J.; et al. Therapeutic target database update 2012: A resource for facilitating target-oriented drug discovery. Nucleic Acids Res. 2012, 40, D1128-D1136. [CrossRef] [PubMed]

24. McCormack, A.I.; Wass, J.A.; Grossman, A.B. Aggressive pituitary tumours: The role of temozolomide and the assessment of mgmt status. Eur. J. Clin. Investig. 2011, 41, 1133-1148. [CrossRef] [PubMed]

25. Riebold, M.; Kozany, C.; Freiburger, L.; Sattler, M.; Buchfelder, M.; Hausch, F.; Stalla, G.K.; Paez-Pereda, M. A c-terminal hsp90 inhibitor restores glucocorticoid sensitivity and relieves a mouse allograft model of cushing disease. Nat. Med. 2015, 21, 276-280. [CrossRef] [PubMed]

26. Ben-Shlomo, A.; Cooper, O. Role of tyrosine kinase inhibitors in the treatment of pituitary tumours: From bench to bedside. Curr. Opin. Endocrinol. Diabetes Obes. 2017, 24, 301-305. [CrossRef] [PubMed]

27. Xu, J.; Wang, P.; Yang, H.; Zhou, J.; Li, Y.; Li, X.; Xue, W.; Yu, C.; Tian, Y.; Zhu, F. Comparison of fda approved kinase targets to clinical trial ones: Insights from their system profiles and drug-target interaction networks. Biomed. Res. Int. 2016, 2016, 2509385. [CrossRef] [PubMed]

28. Zhu, F.; Ma, X.H.; Qin, C.; Tao, L.; Liu, X.; Shi, Z.; Zhang, C.L.; Tan, C.Y.; Chen, Y.Z.; Jiang, Y.Y. Drug discovery prospect from untapped species: Indications from approved natural product drugs. PLoS ONE 2012, 7, e39782. [CrossRef] [PubMed]

29. Li, Y.H.; Wang, P.P.; Li, X.X.; Yu, C.Y.; Yang, H.; Zhou, J.; Xue, W.W.; Tan, J.; Zhu, F. The human kinome targeted by fda approved multi-target drugs and combination products: A comparative study from the drug-target interaction network perspective. PLoS ONE 2016, 11, e0165737. [CrossRef]

30. Lin, A.L.; Jonsson, P.; Tabar, V.; Yang, T.J.; Cuaron, J.; Beal, K.; Cohen, M.; Postow, M.; Rosenblum, M.; Shia, J.; et al. Marked Response of a Hypermutated ACTH-Secreting Pituitary Carcinoma to Ipilimumab and Nivolumab. J. Clin. Endocrinol. Metab. 2018, 103, 3925-3930. [CrossRef]

31. Zhu, F.; Zheng, C.J.; Han, L.Y.; Xie, B.; Jia, J.; Liu, X.; Tammi, M.T.; Yang, S.Y.; Wei, Y.Q.; Chen, Y.Z. Trends in the exploration of anticancer targets and strategies in enhancing the efficacy of drug targeting. Curr. Mol. Pharmacol. 2008, 1, 213-232. [CrossRef] [PubMed]

32. Tao, L.; Zhu, F.; Xu, F.; Chen, Z.; Jiang, Y.Y.; Chen, Y.Z. Co-targeting cancer drug escape pathways confers clinical advantage for multi-target anticancer drugs. Pharmacol. Res. 2015, 102, 123-131. [CrossRef] [PubMed]

33. Li, Y.H.; Li, X.; Hong, J.; Wang, Y.; Fu, J.; Yang, H.; Yu, C.; Li, F.; Hu, J.; Xue, W.W.; et al. Clinical trials, progression-speed differentiating features, and swiftness rule of the innovative targets of first-in-class drugs. Brief. Bioinform. 2019. [CrossRef] 
34. Kourelis, T.V.; Buckner, J.C.; Gangat, N.; Patnaik, M.M. Temozolomide induced bone marrow suppression-A single institution outcome analysis and review of the literature. Am. J. Hematol. 2015, 90, E183-E184. [CrossRef] [PubMed]

35. Li, X.F.; Li, X.X.; Li, Y.H.; Yu, C.Y.; Xue, W.W.; Hu, J.; Li, B.; Wang, P.P.; Zhu, F. What makes species productive of anti-cancer drugs? Clues from drugs' species origin, druglikeness, target and pathway. Anticancer Agents Med. Chem. 2018. [CrossRef] [PubMed]

36. Xue, W.; Wang, P.; Tu, G.; Yang, F.; Zheng, G.; Li, X.; Li, X.; Chen, Y.; Yao, X.; Zhu, F. Computational identification of the binding mechanism of a triple reuptake inhibitor amitifadine for the treatment of major depressive disorder. Phys. Chem. Chem. Phys. 2018, 20, 6606-6616. [CrossRef] [PubMed]

37. Yagnik, G.; Jahangiri, A.; Chen, R.; Wagner, J.R.; Aghi, M.K. Role of a p53 polymorphism in the development of nonfunctional pituitary adenomas. Mol. Cell Endocrinol. 2017, 446, 81-90. [CrossRef]

38. Zhu, F.; Han, L.; Zheng, C.; Xie, B.; Tammi, M.T.; Yang, S.; Wei, Y.; Chen, Y. What are next generation innovative therapeutic targets? Clues from genetic, structural, physicochemical, and systems profiles of successful targets. J. Pharmacol. Exp. Ther. 2009, 330, 304-315. [CrossRef] [PubMed]

39. Xue, W.; Fu, T.; Zheng, G.; Tu, G.; Zhang, Y.; Yang, F.; Tao, L.; Yao, L.; Zhu, F. Recent advances and challenges of the drugs acting on monoamine transporters. Curr. Med. Chem. 2018. [CrossRef] [PubMed]

40. Couzin-Frankel, J. Breakthrough of the year 2013. Cancer immunotherapy. Science 2013, 342, 1432-1433. [CrossRef] [PubMed]

41. Zheng, G.; Xue, W.; Yang, F.; Zhang, Y.; Chen, Y.; Yao, X.; Zhu, F. Revealing vilazodone's binding mechanism underlying its partial agonism to the 5-ht1a receptor in the treatment of major depressive disorder. Phys. Chem. Chem. Phys. 2017, 19, 28885-28896. [CrossRef] [PubMed]

42. Smyth, E.C.; Cervantes, A. Immunotherapy is not for all comers in chemotherapy-refractory advanced gastric cancer. Better predictive biomarkers are needed. Ann. Oncol. 2018, 29, 2027-2028. [CrossRef] [PubMed]

43. Wang, P.; Wang, T.; Yang, Y.; Yu, C.; Liu, N.; Yan, C. Detection of programmed death ligand 1 protein and cd8+ lymphocyte infiltration in plurihormonal pituitary adenomas: A case report and review of the literatures. Medicine 2017, 96, e9056. [CrossRef]

44. Kaliszczak, M.; van Hechanova, E.; Li, Y.; Alsadah, H.; Parzych, K.; Auner, H.W.; Aboagye, E.O. The hdac6 inhibitor c1a modulates autophagy substrates in diverse cancer cells and induces cell death. Br. J. Cancer 2018, 119, 1278-1287. [CrossRef] [PubMed]

45. Xue, W.; Wang, P.; Li, B.; Li, Y.; Xu, X.; Yang, F.; Yao, X.; Chen, Y.Z.; Xu, F.; Zhu, F. Identification of the inhibitory mechanism of fda approved selective serotonin reuptake inhibitors: An insight from molecular dynamics simulation study. Phys. Chem. Chem. Phys. 2016, 18, 3260-3271. [CrossRef]

46. Zheng, G.; Xue, W.; Wang, P.; Yang, F.; Li, B.; Li, X.; Li, Y.; Yao, X.; Zhu, F. Exploring the inhibitory mechanism of approved selective norepinephrine reuptake inhibitors and reboxetine enantiomers by molecular dynamics study. Sci. Rep. 2016, 6, 26883. [CrossRef] [PubMed]

47. Lang, R.; Gundlach, A.L.; Holmes, F.E.; Hobson, S.A.; Wynick, D.; Hokfelt, T.; Kofler, B. Physiology, signaling, and pharmacology of galanin peptides and receptors: Three decades of emerging diversity. Pharmacol. Rev. 2015, 67, 118-175. [CrossRef] [PubMed]

48. Alsaab, H.O.; Sau, S.; Alzhrani, R.; Tatiparti, K.; Bhise, K.; Kashaw, S.K.; Iyer, A.K. Pd-1 and pd-11 checkpoint signaling inhibition for cancer immunotherapy: Mechanism, combinations, and clinical outcome. Front. Pharmacol. 2017, 8, 561. [CrossRef]

49. Camilletti, M.A.; Ferraris, J.; Abeledo-Machado, A.; Converse, A.; Faraoni, E.Y.; Pisera, D.; Gutierrez, S.; Thomas, P.; Diaz-Torga, G. Participation of membrane progesterone receptor alpha in the inhibitory effect of progesterone on prolactin secretion. J. Neuroendocrinol. 2018, 30, e12614. [CrossRef]

50. Vinay, D.S.; Ryan, E.P.; Pawelec, G.; Talib, W.H.; Stagg, J.; Elkord, E.; Lichtor, T.; Decker, W.K.; Whelan, R.L.; Kumara, H.; et al. Immune evasion in cancer: Mechanistic basis and therapeutic strategies. Semin. Cancer Biol. 2015, 35, S185-S198. [CrossRef]

51. Lekva, T.; Berg, J.P.; Fougner, S.L.; Olstad, O.K.; Ueland, T.; Bollerslev, J. Gene expression profiling identifies esrp1 as a potential regulator of epithelial mesenchymal transition in somatotroph adenomas from a large cohort of patients with acromegaly. J. Clin. Endocrinol. Metab. 2012, 97, E1506-E1514. [CrossRef] [PubMed] 
52. Hussaini, I.M.; Trotter, C.; Zhao, Y.; Abdel-Fattah, R.; Amos, S.; Xiao, A.; Agi, C.U.; Redpath, G.T.; Fang, Z.; Leung, G.K.; et al. Matrix metalloproteinase-9 is differentially expressed in nonfunctioning invasive and noninvasive pituitary adenomas and increases invasion in human pituitary adenoma cell line. Am. J. Pathol. 2007, 170, 356-365. [CrossRef] [PubMed]

53. Wierinckx, A.; Roche, M.; Raverot, G.; Legras-Lachuer, C.; Croze, S.; Nazaret, N.; Rey, C.; Auger, C.; Jouanneau, E.; Chanson, P.; et al. Integrated genomic profiling identifies loss of chromosome 11p impacting transcriptomic activity in aggressive pituitary prl tumors. Brain Pathol. 2011, 21, 533-543. [CrossRef] [PubMed]

54. Yang, F.; Zheng, G.; Fu, T.; Li, X.; Tu, G.; Li, Y.H.; Yao, X.; Xue, W.; Zhu, F. Prediction of the binding mode and resistance profile for a dual-target pyrrolyl diketo acid scaffold against hiv-1 integrase and reverse-transcriptase-associated ribonuclease h. Phys. Chem. Chem. Phys. 2018, 20, 23873-23884. [CrossRef] [PubMed]

55. Sav, A.; Rotondo, F.; Syro, L.V.; Scheithauer, B.W.; Kovacs, K. Biomarkers of pituitary neoplasms. Anticancer Res. 2012, 32, 4639-4654. [PubMed]

56. Suhardja, A.; Kovacs, K.; Greenberg, O.; Scheithauer, B.W.; Lloyd, R.V. Prognostic indicators in pituitary tumors. Endocr. Pathol. 2005, 16,1-9. [CrossRef]

57. Di Ieva, A.; Rotondo, F.; Syro, L.V.; Cusimano, M.D.; Kovacs, K. Aggressive pituitary adenomas-diagnosis and emerging treatments. Nat. Rev. Endocrinol. 2014, 10, 423-435. [CrossRef] [PubMed]

58. Raverot, G.; Castinetti, F.; Jouanneau, E.; Morange, I.; Figarella-Branger, D.; Dufour, H.; Trouillas, J.; Brue, T. Pituitary carcinomas and aggressive pituitary tumours: Merits and pitfalls of temozolomide treatment. Clin. Endocrinol. 2012, 76, 769-775. [CrossRef]

59. Snyder, A.; Makarov, V.; Merghoub, T.; Yuan, J.; Zaretsky, J.M.; Desrichard, A.; Walsh, L.A.; Postow, M.A.; Wong, P.; Ho, T.S.; et al. Genetic basis for clinical response to ctla-4 blockade in melanoma. N. Engl. J. Med. 2014, 371, 2189-2199. [CrossRef]

60. Mistry, M.; Gillis, J.; Pavlidis, P. Genome-wide expression profiling of schizophrenia using a large combined cohort. Mol. Psychiatry 2013, 18, 215-225. [CrossRef]

61. Morris, D.G.; Musat, M.; Czirjak, S.; Hanzely, Z.; Lillington, D.M.; Korbonits, M.; Grossman, A.B. Differential gene expression in pituitary adenomas by oligonucleotide array analysis. Eur. J. Endocrinol. 2005, 153, $143-151$. [CrossRef] [PubMed]

62. Michaelis, K.A.; Knox, A.J.; Xu, M.; Kiseljak-Vassiliades, K.; Edwards, M.G.; Geraci, M.; Kleinschmidt-DeMasters, B.K.; Lillehei, K.O.; Wierman, M.E. Identification of growth arrest and DNA-damage-inducible gene beta (GADD45beta) as a novel tumor suppressor in pituitary gonadotrope tumors. Endocrinology 2011, 152, 3603-3613. [CrossRef] [PubMed]

63. Tong, Y.; Zheng, Y.; Zhou, J.; Oyesiku, N.M.; Koeffler, H.P.; Melmed, S. Genomic characterization of human and rat prolactinomas. Endocrinology 2012, 153, 3679-3691. [CrossRef] [PubMed]

64. Yu, S.Y.; Hong, L.C.; Feng, J.; Wu, Y.T.; Zhang, Y.Z. Integrative proteomics and transcriptomics identify novel invasive-related biomarkers of non-functioning pituitary adenomas. Tumour Biol. 2016, 37, 8923-8930. [CrossRef]

65. Maudsley, S.; Devanarayan, V.; Martin, B.; Geerts, H.; Brain Health Modeling, I. Intelligent and effective informatic deconvolution of "big data" and its future impact on the quantitative nature of neurodegenerative disease therapy. Alzheimers Dement. 2018, 14, 961-975. [CrossRef]

66. Date, Y.; Kikuchi, J. Application of a deep neural network to metabolomics studies and its performance in determining important variables. Anal. Chem. 2018, 90, 1805-1810. [CrossRef] [PubMed]

67. Song, L.; Zhuang, P.; Lin, M.; Kang, M.; Liu, H.; Zhang, Y.; Yang, Z.; Chen, Y.; Zhang, Y. Urine metabonomics reveals early biomarkers in diabetic cognitive dysfunction. J. Proteome Res. 2017, 16, 3180-3189. [CrossRef]

68. Zhou, Z.; Shen, X.; Tu, J.; Zhu, Z.J. Large-scale prediction of collision cross-section values for metabolites in ion mobility-mass spectrometry. Anal. Chem. 2016, 88, 11084-11091. [CrossRef]

69. Hart, C.D.; Vignoli, A.; Tenori, L.; Uy, G.L.; Van To, T.; Adebamowo, C.; Hossain, S.M.; Biganzoli, L.; Risi, E.; Love, R.R.; et al. Serum metabolomic profiles identify er-positive early breast cancer patients at increased risk of disease recurrence in a multicenter population. Clin. Cancer Res. 2017, 23, 1422-1431. [CrossRef]

70. Yu, C.Y.; Li, X.X.; Yang, H.; Li, Y.H.; Xue, W.W.; Chen, Y.Z.; Tao, L.; Zhu, F. Assessing the performances of protein function prediction algorithms from the perspectives of identification accuracy and false discovery rate. Int. J. Mol. Sci. 2018, 19, 183. [CrossRef] 
71. Hou, W.; Meng, X.; Zhao, A.; Zhao, W.; Pan, J.; Tang, J.; Huang, Y.; Li, H.; Jia, W.; Liu, F.; et al. Development of multimarker diagnostic models from metabolomics analysis for gestational diabetes mellitus (gdm). Mol. Cell. Proteom. 2018, 17, 431-441. [CrossRef] [PubMed]

72. Alonso, A.; Julia, A.; Vinaixa, M.; Domenech, E.; Fernandez-Nebro, A.; Canete, J.D.; Ferrandiz, C.; Tornero, J.; Gisbert, J.P.; Nos, P.; et al. Urine metabolome profiling of immune-mediated inflammatory diseases. BMC Med. 2016, 14, 133. [CrossRef] [PubMed]

73. Wu, F.; Chi, L.; Ru, H.; Parvez, F.; Slavkovich, V.; Eunus, M.; Ahmed, A.; Islam, T.; Rakibuz-Zaman, M.; Hasan, R.; et al. Arsenic exposure from drinking water and urinary metabolomics: Associations and long-term reproducibility in bangladesh adults. Environ. Health Perspect. 2018, 126, 017005. [CrossRef] [PubMed]

74. Valikangas, T.; Suomi, T.; Elo, L.L. A systematic evaluation of normalization methods in quantitative label-free proteomics. Brief. Bioinform. 2018, 19, 1-11. [CrossRef] [PubMed]

75. Wang, C.; Gong, B.; Bushel, P.R.; Thierry-Mieg, J.; Thierry-Mieg, D.; Xu, J.; Fang, H.; Hong, H.; Shen, J.; $\mathrm{Su}, \mathrm{Z}$.; et al. The concordance between rna-seq and microarray data depends on chemical treatment and transcript abundance. Nat. Biotechnol. 2014, 32, 926-932. [CrossRef] [PubMed]

76. Jameson, J.L.; Klibanski, A.; Black, P.M.; Zervas, N.T.; Lindell, C.M.; Hsu, D.W.; Ridgway, E.C.; Habener, J.F. Glycoprotein hormone genes are expressed in clinically nonfunctioning pituitary adenomas. J. Clin. Investig. 1987, 80, 1472-1478. [CrossRef] [PubMed]

77. Leung, B.; Iisma, T.P.; Leung, K.C.; Hort, Y.J.; Turner, J.; Sheehy, J.P.; Ho, K.K. Galanin in human pituitary adenomas: Frequency and clinical significance. Clin. Endocrinol. 2002, 56, 397-403. [CrossRef]

78. La Rosa, S.; Vigetti, D.; Placidi, C.; Finzi, G.; Uccella, S.; Clerici, M.; Bartolini, B.; Carnevali, I.; Losa, M.; Capella, C. Localization of carboxyl ester lipase in human pituitary gland and pituitary adenomas. J. Histochem. Cytochem. 2010, 58, 881-889. [CrossRef]

79. Zebracka-Gala, J.; Rudnik, A.; Hasse-Lazar, K.; Larysz, D.; Jarzab, M.; Krajewska, J.; Bazowski, P.; Jarzab, B. Molecular classification of pituitary adenomas: In search for criteria useful for high-throughput studies. Endokrynol. Pol. 2016, 67, 148-156.

80. Woloschak, M.; Roberts, J.L.; Post, K. C-myc, c-fos, and c-myb gene expression in human pituitary adenomas. J. Clin. Endocrinol. Metab. 1994, 79, 253-257.

81. Jiang, Z.; Gui, S.; Zhang, Y. Analysis of differential gene expression by bead-based fiber-optic array in nonfunctioning pituitary adenomas. Horm. Metab. Res. 2011, 43, 325-330. [CrossRef] [PubMed]

82. Tohti, M.; Li, J.; Tang, C.; Wen, G.; Abdujilil, A.; Yizim, P.; Ma, C. Serum agr2 as a useful biomarker for pituitary adenomas. Clin. Neurol. Neurosurg. 2017, 154, 19-22. [CrossRef] [PubMed]

83. Zhou, X.; Gomez-Smith, M.; Qin, Z.; Duquette, P.M.; Cardenas-Blanco, A.; Rai, P.S.; Harper, M.E.; Tsai, E.C.; Anisman, H.; Chen, H.H. Ablation of $1 \mathrm{mo} 4$ in glutamatergic neurons impairs leptin control of fat metabolism. Cell. Mol. Life Sci. 2012, 69, 819-828. [CrossRef] [PubMed]

84. Marzec, M.; Zhang, Q.; Goradia, A.; Raghunath, P.N.; Liu, X.; Paessler, M.; Wang, H.Y.; Wysocka, M.; Cheng, M.; Ruggeri, B.A.; et al. Oncogenic kinase npm/alk induces through stat3 expression of immunosuppressive protein cd274 (pd-11, b7-h1). Proc. Natl. Acad. Sci. USA 2008, 105, 20852-20857. [CrossRef] [PubMed]

85. Barrett, T.; Wilhite, S.E.; Ledoux, P.; Evangelista, C.; Kim, I.F.; Tomashevsky, M.; Marshall, K.A.; Phillippy, K.H.; Sherman, P.M.; Holko, M.; et al. Ncbi geo: Archive for functional genomics data sets-Update. Nucleic Acids Res. 2013, 41, D991-D995. [CrossRef] [PubMed]

86. Tippmann, S. Programming tools: Adventures with r. Nature 2015, 517, 109-110. [CrossRef] [PubMed]

87. Lazar, C.; Meganck, S.; Taminau, J.; Steenhoff, D.; Coletta, A.; Molter, C.; Weiss-Solis, D.Y.; Duque, R.; Bersini, H.; Nowe, A. Batch effect removal methods for microarray gene expression data integration: A survey. Brief. Bioinform. 2013, 14, 469-490. [CrossRef] [PubMed]

88. Fu, J.; Tang, J.; Wang, Y.; Cui, X.; Yang, Q.; Hong, J.; Li, X.; Li, S.; Chen, Y.; Xue, W.; et al. Discovery of the consistently well-performed analysis chain for swath-ms based pharmacoproteomic quantification. Front. Pharmacol. 2018, 9, 681. [CrossRef]

89. Tang, J.; Fu, J.; Wang, Y.; Li, B.; Li, Y.H.; Yang, Q.; Cui, X.; Hong, J.; Li, X.; Chen, Y.Z.; et al. Anpela: Analysis and performance-assessment of the label-free quantification workflow for metaproteomic studies. Brief. Bioinform. 2019. [CrossRef] 
90. Smyth, G.K. Linear models and empirical bayes methods for assessing differential expression in microarray experiments. Stat. Appl. Genet. Mol. Biol. 2004, 3, 3. [CrossRef]

91. Ritchie, M.E.; Phipson, B.; Wu, D.; Hu, Y.; Law, C.W.; Shi, W.; Smyth, G.K. Limma powers differential expression analyses for rna-sequencing and microarray studies. Nucleic Acids Res. 2015, 43, e47. [CrossRef]

92. Grames, M.S.; Dayton, R.D.; Jackson, K.L.; Richard, A.D.; Lu, X.; Klein, R.L. Cre-dependent aav vectors for highly targeted expression of disease-related proteins and neurodegeneration in the substantia nigra. FASEB J. 2018, 32, 4420-4427. [CrossRef] [PubMed]

93. Subramanian, A.; Tamayo, P.; Mootha, V.K.; Mukherjee, S.; Ebert, B.L.; Gillette, M.A.; Paulovich, A.; Pomeroy, S.L.; Golub, T.R.; Lander, E.S.; et al. Gene set enrichment analysis: A knowledge-based approach for interpreting genome-wide expression profiles. Proc. Natl. Acad. Sci. USA 2005, 102, 15545-15550. [CrossRef] [PubMed]

94. Pochet, N.; De Smet, F.; Suykens, J.A.; De Moor, B.L. Systematic benchmarking of microarray data classification: Assessing the role of non-linearity and dimensionality reduction. Bioinformatics 2004, 20, 3185-3195. [CrossRef] [PubMed]

95. Li, B.; Tang, J.; Yang, Q.; Cui, X.; Li, S.; Chen, S.; Cao, Q.; Xue, W.; Chen, N.; Zhu, F. Performance evaluation and online realization of data-driven normalization methods used in lc/ms based untargeted metabolomics analysis. Sci. Rep. 2016, 6, 38881. [CrossRef]

96. Murakami, Y.; Spriggs, R.V.; Nakamura, H.; Jones, S. Piranha: A server for the computational prediction of rna-binding residues in protein sequences. Nucleic Acids Res. 2010, 38, W412-W416. [CrossRef]

97. Simurina, M.; de Haan, N.; Vuckovic, F.; Kennedy, N.A.; Stambuk, J.; Falck, D.; Trbojevic-Akmacic, I.; Clerc, F.; Razdorov, G.; Khon, A.; et al. Glycosylation of immunoglobulin g associates with clinical features of inflammatory bowel diseases. Gastroenterology 2018, 154, 1320-1333. [CrossRef]

98. Li, B.; Tang, J.; Yang, Q.; Li, S.; Cui, X.; Li, Y.; Chen, Y.; Xue, W.; Li, X.; Zhu, F. Noreva: Normalization and evaluation of ms-based metabolomics data. Nucleic Acids Res. 2017, 45, W162-W170. [CrossRef]

99. Brindisi, M.; Senger, J.; Cavella, C.; Grillo, A.; Chemi, G.; Gemma, S.; Cucinella, D.M.; Lamponi, S.; Sarno, F.; Iside, C.; et al. Novel spiroindoline hdac inhibitors: Synthesis, molecular modelling and biological studies. Eur. J. Med. Chem. 2018, 157, 127-138. [CrossRef]

100. Szklarczyk, D.; Morris, J.H.; Cook, H.; Kuhn, M.; Wyder, S.; Simonovic, M.; Santos, A.; Doncheva, N.T.; Roth, A.; Bork, P.; et al. The string database in 2017: Quality-controlled protein-protein association networks, made broadly accessible. Nucleic Acids Res. 2017, 45, D362-D368. [CrossRef]

101. Shannon, P.; Markiel, A.; Ozier, O.; Baliga, N.S.; Wang, J.T.; Ramage, D.; Amin, N.; Schwikowski, B.; Ideker, T. Cytoscape: A software environment for integrated models of biomolecular interaction networks. Genome Res. 2003, 13, 2498-2504. [CrossRef] [PubMed]

(C) 2019 by the authors. Licensee MDPI, Basel, Switzerland. This article is an open access article distributed under the terms and conditions of the Creative Commons Attribution (CC BY) license (http://creativecommons.org/licenses/by/4.0/). 